\title{
Conflict Management Strategies of Career Counsellors
}

\author{
Andreas Frey¹, Eric Bühler², Jean-Jacques Ruppert ${ }^{3}$ \\ ${ }^{1}$ University of Applied Labour Studies (HdBA), Mannheim, Germany \\ ${ }^{2}$ Higher School for Technology and Management (sfb), Dietikon, Switzerland \\ ${ }^{3}$ Applied Vocational Psychology and Policy Research Unit (AVOPP), Belvaux, Luxembourg \\ Email: Andreas.Frey@hdba.de, ebuehler@sfb.ch,info@avopp.lu
}

How to cite this paper: Frey, A., Bühler, E., \& Ruppert, J.-J. (2022). Conflict Management Strategies of Career Counsellors. Psychology, 13, 62-77.

https://doi.org/10.4236/psych.2022.131005

Received: September 28, 2021

Accepted: January 17, 2022

Published: January 20, 2022

Copyright (C) 2022 by author(s) and Scientific Research Publishing Inc. This work is licensed under the Creative Commons Attribution International License (CC BY 4.0).

http://creativecommons.org/licenses/by/4.0/ (c) (i) Open Access

\begin{abstract}
In everyday professional life, career counsellors are confronted with a variety of conflict situations. These conflicts are not related to clients only but also to problems with colleagues, with a service provider or with the team management. For the research group "behaviours of adolescents and young adults in their vocational and study orientation phase and their training and study success", it was important to use the co-ping questionnaire for counsellors to find out which areas of conflict the 346 counsellors surveyed were confronted with, which coping strategies they used, how they assessed these strategies and what connections these behaviours had with personal attitudes and positions. The three most noticeable areas of stress for counsellors were problems with adolescents under 25 years of age and adults over 25 as well as problems with colleagues. Respondents reported that such events were perceived as unpleasant/stressful and were of great significance to them. According to a self-assessment, $72 \%$ of the counsellors were able to cope successfully with the problem. The predictability and duration of such problems had only a secondary influence on successful coping.
\end{abstract}

\section{Keywords}

Career Counsellor, Coping Strategies, Vocational Guidance, Counselling Competence

\section{Introduction}

Conflict management strategies are of great importance to career counsellors in difficult professional situations as the counselling of young people and adults should always take place in a conflict-free context (Ertelt et al., in press; Ulrich, 
2021). Career counsellors may be faced with different conflict situations in their everyday professional life. Such conflicts are not only related to young people or adults in vocational guidance, further education or career counselling, but there may also be e.g. problems with colleagues or team management. There is a multitude of other factors that can lead to conflict situations in counselling. The conflicts career counsellors refer to are important, but it also matters to find out how they deal with them, what coping strategies they have at their disposal, how they implement them and what correlations there are between certain behaviours and the counsellors' work environments, e.g. (Labrague et al., 2016; Obi \& Obineli, 2015; Ulrich, 2020).

Within the framework of the research project "Behaviours of adolescents and young adults in their vocational and study orientation phase and their success in training and studies" (BSOP), we examined the coping strategies used by career counsellors in vocational situations, looked at how helpful the behaviours shown were and which effects or causes could be attributed to these behaviours.

\section{Conflict Management Strategies (Coping Strategies)}

According to Neubauer \& Winter (2007) there are conflict prevention strategies and there is conflict potential. The conflict potential consists of cognitive and affective processes that precede an argument. Whether this then leads to an open conflict depends on the outcome of this confrontation. This is where conflict prevention strategies come into play which can include the following aspects:

- Frustration tolerance, i.e. enduring a negative situation for a longer period of time without attempting to change it.

- Ambiguity tolerance, i.e. putting up with disagreements and contradictions.

- Reward deferral, i.e. putting current needs on hold for a later gain.

- Role distancing, i.e. the person looking at his or her own behaviour from the point of view of an outsider in order to be able to judge his or her situation objectively.

- Role-taking, i.e. being able to "put oneself in the shoes" of others.

Coping research has its origins in stress research which deals among other things with the origins and effects of stress. Thus coping is usually understood as dealing with problem situations with the objective of the closure of the coping process (Dubow \& Rubinlicht, 2011; Stephenson et al., 2016). Coping implies all coping strategies regardless of whether the coping behaviour displayed is successful or not. The next paragraph presents among the common approaches in coping research those that are related to the coping questionnaire used in this study.

\section{Model Approaches in Coping Research}

The heuristic model of Filipp (1981) is based on the assumption that the processuality of an event, the relationship between a person and his or her envi- 
ronment and the active dealing with that event, constitute the process of coping. Person and environment here form a system. When a critical event occurs, contradictions arise in the person-environment dyad with the task of establishing a new balance. In this model you find the following analytical units that are significant for a person's coping and confrontation behaviour:

\section{- Antecedent conditions (antecedent characteristics)}

Here a person's biography is taken into account with the main focus on past critical events and how they were dealt with.

\section{- Competing conditions}

Here personal characteristics such as biological, psychological and biophysical characte-ristics such as personality factors and physical strength as well as contextual characteristics such as the social and ecological environment the person is involved in when in confrontation and coping processes are taken into account.

\section{- Event characteristics}

Characteristics of critical life events are divided into objective, objectifiable and subjective event parameters.

\section{- Process characteristics}

Here a person's ways of dealing and coping with critical life events at different levels of his or her behavioural system play a part.

\section{- Consequence characteristics}

Here the effects of confronting and coping with a life event are taken into consideration.

Depending on the event, person-related, interactional and environment-related effects (Filipp, 1981) as well as group-specific effects (Wang \& Wu, 2020) can arise.

Lumsden (1975)'s assumption that coping is a processual event is fundamental to Jäger (1989)'s model, see also (Behfar et al., 2011). A critical event occurs, the person perceives it and deals with it. As a result of the confrontation the person then tries to cope with the event and thus arrives at a re-evaluation of the situation. According to Lumsden (1975) coping takes place when a person's life situation changes and he or she has to come up with new ways of dealing with the situation. There are three types of coping response: physiological, behavioural and cognitive. What is significant about the process-analytic model is that it includes elements of a person's self-regulation (Lumsden, 1975: 195 p).

Jäger (1989) has added to these aspects of his model the action reference which includes the two coping reactions confrontation and displacement. According to Jäger confrontation is the "conscious and/or purposeful way of coping" while displacement is the "conscious or unconscious mechanism for not wanting to acknowledge a given problem" (ibid., p. 79).

Furthermore, Jäger added a time reference to Lumsden's process-analytical model which consists of the past (biography and the related repertoire of existing coping strategies), the present (supporting or inhibiting situational mecha- 
nisms) and the future (as anticipation of conditions and consequences) (Jäger, 1989: 79 p). This model assumes that a critical event is evaluated differently by different persons. However, the intentions associated with the coping behaviour are not taken into account. As a rule, one does not know during the execution of an action the reason for displaying a particular behaviour and one becomes aware of the significance of this course of action after some time only.

With the coping questionnaire presented here, an attempt was made to describe a model that encompasses the complexity of coping behaviours. The questionnaire therefore not only asks questions about coping behaviours in difficult situations but also about intentions and subjective assessments associated with coping reactions.

\section{The Coping Questionnaire}

The coping questionnaire is based on the description of an event, on its subjective assessment, the coping reactions and the associated intentions and efficiency assessments.

At the beginning of the questionnaire, the respondent indicates a situation he or she perceived as unpleasant in the last four weeks. If the respondent reacted to this unpleasant situation with a coping behaviour specified in the questionnaire, this behaviour is evaluated as successful or unsuccessful. Accompanying physiological reactions, as well as emotional reactions that may be generated by problem situations are recorded in the last part of the questionnaire. When asked about their coping reactions, the respondents have the option of answering the question in the affirmative or in the negative. If they answer the question in the negative, they can move on to the next item; if they answer the question in the affirmative, the respondents can tick the intentions associated with the coping behaviour shown.

For the study "Behaviours of adolescents and young adults in the vocational and academic orientation phase and their educational and academic success" by Frey \& Ruppert (2020), a version consisting of 76 items divided into four categories was chosen:

\section{- Cognitive engagement}

This means finding possible solutions, attribution, making sense of and/or accepting an event.

\section{- Actional engagement}

Information and/or new activities are sought in order to actively change the problem. The search for social support and "fighting back" are also part of this category.

\section{- Cognitive avoidance}

Here the person refuses to acknowledge to him- or herself as well as to others that there is a problem, he or she resigns, is depressed, indifferent, uninvolved, helpless and/or tries to trivialize the problem.

- Actional avoidance 
The problem is covered up, the person tries to avoid the unpleasant situation and/or distracts him- or herself, withdraws, runs away from the problem and/or feels sorry for him- or herself.

\section{Results}

\section{Description of the sample}

A total of 346 career counsellors participated in the study which ran from November 2019 to March 2020. 225 respondents (65\%) were female and 121 (35\%) were male. The average age was 43.6 years.

\section{Results on the problem descriptions}

All 346 career counsellors were asked to enter in the coping questionnaire an unpleasant event that they had experienced in their everyday working life in the last four weeks and then to classify the issue described into one of 15 problem categories. The response rate was $89 \%$. A total of 308 assignments were recorded in nine categories (cf. Table 1).

Table 1 reveals the following: The most conspicuous areas of stress for career counsellors are problems with clients aged over 25, problems with colleagues and problems with clients under 25.

When the career guidance counsellors were asked whether these problems primarily affect themselves or other people, the following distribution emerged.

The result in Table 2 shows that in $64 \%$ of all cases the career counsellors

Table 1. Distribution of problem categories.

\begin{tabular}{ccc}
\hline Category & $\boldsymbol{n}$ & $\boldsymbol{f \%}_{\text {total }}$ \\
\hline Problems with clients aged $>25$ & 91 & 29.6 \\
Problems with colleagues & 52 & 17.0 \\
Problems with clients aged $<25$ & 49 & 15.9 \\
Problems with team leadership & 25 & 8.1 \\
Problems with self & 22 & 7.1 \\
Problems with job description & 21 & 6.8 \\
Problems with school & 18 & 5.8 \\
Problems with employer & 17 & 5.5 \\
Problems with a school class & 13 & 4.2 \\
Total & 308 & 100 \\
\hline
\end{tabular}

Legend: $n=$ Number of respondents; $f \%$ total distribution in $\%$ for the total sample.

Table 2. Concern.

\begin{tabular}{cc}
\hline Category & Answers in \% \\
\hline Affects myself & $64 \%$ \\
Affects another person & $36 \%$ \\
\hline
\end{tabular}


reported stressful events that affected themselves. The respondents also stated that the event was perceived as unpleasant/stressful but that it was furthermore of great significance to them. During the event the respondents were sometimes powerless or paralyzed by the process as they rarely have to deal with such problems.

According to a self-assessment $72 \%$ of the respondents were able to cope with the problem successfully; in $68 \%$ of the cases the event could not have been foreseen and for $59 \%$ of the respondents it was not a long-term problem.

t-tests were then used to test the self-assessments of the career counsellors who had stated that they had been unable to successfully manage the problem with those who had said that they had successfully done so, with regard to the assessment of the foreseeability of the problem and the duration of the problem. No significant differences were found $(p>0.05)$. Consequently, the foreseeability and the duration of the problem have a secondary influence only on successful coping.

\section{Results on the action strategies}

Are there now any strategies for action that are a prerequisite for career counsellors to state that they have been able to cope successfully with the problem?

The second part of the questionnaire was intended to provide answers to this question by asking respondents to indicate (tick the case) the thoughts they have had and actions they have undertaken in relation to the problem described. If a question or statement was ticked No, they were to move on to the next question. If a statement was ticked Yes, they should indicate how helpful this behaviour had been for them on a 4 -point scale $(1=$ very helpful to $4=$ not helpful at all).

In the following, the coping strategies that were selected by the respondents for problem solving are shown. Only those respondents who had used at least one item from the respective category were included in the calculations. The mere use of the coping strategies does at this stage not provide any information as to whether the behaviour shown was also helpful in solving the problem.

\section{- Actional coping strategies}

Total of the items: 3, 13, 16, $21-26,31,40,42,46-48,59,68$ (possible maximum value: 17 ; possible minimum value: 1 ).

The results from Table 3 can be interpreted as follows: 301 career guidance counsellors dealt with the problem they were facing in an action-oriented way. For about $47 \%$ of the respondents, a maximum of 13 action alternatives were used in this category. The evaluation shows that on average about seven action alternatives were used in the category of actional confrontation.

Table 3. Mean value for actional engagement.

\begin{tabular}{ccccc}
\hline $\boldsymbol{n}$ & $\boldsymbol{M}$ & $\boldsymbol{s}$ & $\boldsymbol{W}_{\boldsymbol{n}}$ & $\boldsymbol{W}_{\boldsymbol{h}}$ \\
\hline 301 & 7.1 & 2.7 & 1 & 13 \\
\hline
\end{tabular}

Legend: $n=$ Number of respondents; $M=$ Mean; $s=$ Standard deviation; $W_{n}=$ lowest total value; $W_{h}=$ highest total value. 


\section{- Actional avoidance strategies}

Total of the items: $4,5,7,32-35,50,54,60,61,66,70-76$ (possible maximum value: 19 ; possible minimum value: 1 ).

Table 4 shows the following picture: 266 career guidance counsellors displayed actional avoidance strategies with regard to the problem they were facing; however $87 \%$ of the respondents used a maximum of five action alternatives. On average about three action alternatives came into play in the category of actional avoidance.

\section{- Cognitive strategies of confrontation}

Total of items: 1, 2, 6, 9 - 11, 14, 15, 20, 29, 30, 36-39, 44, 52, 55 - 58, 62, 63, 67 (possible maximum value: 24 ; possible minimum value: 1 ).

Table 5 shows that 304 career counsellors also dealt with the problem they were facing on a cognitive level. For $72 \%$ of the respondents more than 12 alternative courses of action were used. The mean value shows that on average 14 alternative courses of action were used for cognitive confrontation.

\section{- Cognitive avoidance strategies}

Total of items: 8, 12, 17 - 19, 23, 27, 28, 41, 43, 45, 49, 51, 53, 64, 65, 69 (possible maximum value: 17 ; possible minimum value: 1 ).

Table 6 shows the following picture: 249 career counsellors stated relying on cognitive avoidance strategies to solve the problem. For $86 \%$ of the respondents a maximum of six alternative courses of action were used. A mean value of four alternative courses of action shows that on average four of the stated coping strategies were actually used.

The results from Tables 3-6 can be interpreted as follows: Firstly, in order to cope with a problem, the interviewed career counsellors primarily used a variety

Table 4. Mean value for actional avoidance.

\begin{tabular}{ccccc}
\hline $\boldsymbol{n}$ & $\boldsymbol{M}$ & $\boldsymbol{s}$ & $W_{\boldsymbol{n}}$ & $W_{\boldsymbol{h}}$ \\
\hline 266 & 2.8 & 2 & 1 & 10
\end{tabular}

Legend: $n=$ Number of respondents; $M=$ Mean; $s=$ Standard deviation; $W_{n}=$ lowest total value; $W_{h}=$ highest total value.

Table 5. Mean score for cognitive engagement.

\begin{tabular}{ccccc}
\hline $\boldsymbol{n}$ & $\boldsymbol{M}$ & $\boldsymbol{s}$ & $\boldsymbol{W}_{\boldsymbol{n}}$ & $\boldsymbol{W}_{\boldsymbol{h}}$ \\
\hline 304 & 13.9 & 5.1 & 1 & 23 \\
\hline
\end{tabular}

Legend: $n=$ Number of respondents; $M=$ Mean; $s=$ Standard deviation; $W_{n}=$ lowest total value; $W_{h}=$ highest total value.

Table 6. Mean value for cognitive avoidance.

\begin{tabular}{ccccc}
\hline $\boldsymbol{n}$ & $\boldsymbol{M}$ & $\boldsymbol{s}$ & $W_{n}$ & $W_{\boldsymbol{h}}$ \\
\hline 249 & 3.9 & 2.6 & 1 & 11 \\
\hline
\end{tabular}

Legend: $n=$ Number of respondents; $M=$ Mean; $s=$ Standard deviation; $W_{n}=$ lowest total value; $W_{h}=$ highest total value. 
of cognitive and actional coping strategies. Secondly, they used cognitive avoidance strategies to avoid the problem, followed by actional avoidance. In summary, it can be said that career counsellors dealt with the problem they were facing both cognitively and actionally.

Are there any correlations among career counsellors between actional and cognitive coping or action strategies on one hand and actional and cognitive avoidance strategies on the other? A correlation calculation should provide the first answer to this question.

Although there are significant correlations between all action strategies, the correlations of Table 7 show that the action strategies cognitive/actional avoidance $(r=0.71)$ and cognitive/actional engagement $(r=0.61)$ are much more strongly related. Furthermore, one can assume that career counsellors used both confrontation and avoidance strategies within a conflict situation.

If on a general level, the action strategies in all of the problem areas presented are characterized by the use of all of the action alternatives, we should check on the basis of the four most frequently mentioned problem situations whether the action strategies were selected specifically with regard to the problems the counsellors were facing and were not ruled by a change in action strategy. Three correlation matrices are to provide an insight into problem-oriented correlations of action strategies.

With regard to 'Problems with adults over 25 years of age', the correlations from Table 8 show the following picture: there are significant correlations between the action strategies of actional and cognitive engagement $(\mathrm{r}=0.49 . p<0.01)$, actional and cognitive avoidance $(r=0.68, p<0.01)$ and actional engagement and

Table 7. Correlation matrix.

\begin{tabular}{lccc}
\hline & Act.Engag. & Cog.Engag. & Act.Avoid. \\
\hline Cog.Engag. & $0.61^{\star \star}$ & & \\
Act.Avoid. & $0.27^{\star \star}$ & $0.19^{\star}$ & \\
Cog.Avoid. & $0.28^{\star \star}$ & $0.21^{\star}$ & $0.71^{\star \star}$ \\
\hline
\end{tabular}

Legend: Act.Engag. = Actional Engagement; Cog.Engag. = Cognitive Engagement; Act.Avoid. = Actional Avoidance; Cog.Avoid. $=$ Cognitive Avoidance; ${ }^{\star} p<0.05 ;{ }^{\star *} p<$ 0.01 .

Table 8. Correlation matrix "problems with adults over 25 years of age".

\begin{tabular}{cccc}
\hline & Act.Engag. & Cog.Engag. & Act.Avoid. \\
\hline Cog.Engag. & $0.49^{* *}$ & & \\
Act.Avoid. & 0.18 & 0.17 & \\
Cog.Avoid. & $0.46^{* *}$ & 0.25 & $0.68^{* *}$ \\
\hline
\end{tabular}

Legend: Act.Engag. = Actional Engagement; Cog.Engag. = Cognitive Engagement; Act.Avoid. = Actional Avoidance; Cog.Avoid. $=$ Cognitive Avoidance; ${ }^{\star} p<0.05 ;{ }^{\star \star} p<$ 0.01 . 
cognitive avoidance $(r=0.46, p<0.01)$. Here, the coping behaviour of the career counsellors is characterized by a change in strategy (=not just following one strategy but switching between confrontation and avoidance strategies). This means e.g. that these individuals first confronted the problems and, after that behaviour had failed, avoided the problems.

With regard to "problems with colleagues", the correlations in Table 9 show that primarily actional and cognitive avoidance strategies $(\mathrm{r}=0.56, p<0.05)$ were used by the career counsellors. The respondents who indicated stressful situations with colleagues as a problem area dealt with them through actional and cognitive avoidance behaviours, i.e they did then not use active conflict management behaviours but preferred to behave in a restrained/repressive manner.

The correlations in Table 10 show that career counsellors who reported “problems with clients under the age of 25 " preferred the following action strategies: Actional and cognitive engagement $(r=0.61, p<0.01)$, actional and cognitive avoidance $(r=0.52, \mathrm{p}<0.01)$ and actional engagement coupled with actional avoidance $(\mathrm{r}=0.36, p<0.05)$. Again it can be seen that the coping behaviour of the respondents was characterized by a change in strategy. This specifically means that if a previously adopted strategy had not been successful, another one was used.

In summary, it can be stated that career counsellors tended very strongly towards a change in strategy with regard to action strategies, i.e. they did not only use one action strategy, e.g. confrontation to cope with a problem but alternated between avoidance and confrontation approaches. However, one exception could

Table 9. Correlation matrix "problems with colleagues".

\begin{tabular}{cccc}
\hline & Act.Engag. & Cog.Engag. & Act.Avoid. \\
\hline Cog.Engag. & 0.33 & & \\
Act.Avoid. & 0.11 & 0.29 & \\
Cog.Avoid. & 0.18 & 0.10 & $0.56^{*}$ \\
\hline
\end{tabular}

Legend: Act.Engag. = Actional Engagement; Cog.Engag. = Cognitive Engagement; Act.Avoid. = Actional Avoidance; Cog.Avoid. $=$ Cognitive Avoidance; ${ }^{\star} p<0.05 ;{ }^{\star *} p<$ 0.01 .

Table 10. Correlation matrix "problems with adolescents under 25 years of age".

\begin{tabular}{cccc}
\hline & Act.Engag. & Cog.Engag. & Act.Avoid. \\
\hline Cog.Engag. & $0.61^{\star *}$ & & \\
Act.Avoid. & $0.36^{\star}$ & 0.25 & \\
Cog.Avoid. & 0.24 & 0.24 & $0.52^{\star *}$ \\
\hline
\end{tabular}

Legend: Act.Engag. = Actional Engagement; Cog.Engag. = Cognitive Engagement; Act.Avoid. = Actional Avoidance; Cog.Avoid. = Cognitive Avoidance; ${ }^{\star} p<0.05 ;{ }^{\star \star} p<$ 0.01 . 
be identified: Conflicts with colleagues were primarily characterized by actional and cognitive avoidance behaviours. In this problem category there was no change in strategy.

The following table shows the overall results when counsellors were asked how helpful the behaviours displayed had been $(1=$ very helpful to $4=$ not helpful at all):

The mean values from Table 11 show that career counsellors who dealt with a problem (actionally and cognitively) rated this approach as unhelpful $(\mathrm{M}=3.3$ and 3.1). Guidance counsellors who dealt with a problem through avoidance (actional and cognitive) rated it as quite helpful ( $\mathrm{M}=2.4$ and 2.1). A repeated-measures analysis of variance indicated that guidance counsellors who used avoidance strategies considered this behaviour more helpful than using confrontation strategies. Nevertheless $72 \%$ of the career counsellors stated that they were from their points of view able to cope successfully with the problem they were facing.

\section{Results on the factor structure}

In order to structure the action strategies, factor analysis was conducted with the total of actional and cognitive confrontation variables as well as of actional and cognitive avoidance variables with a variance clarification of $51.9 \%$. This resulted in two dimensions (orthogonal varimax solution) (See Table 12).

The two dimensions obtained are interpreted in the following way, whereby this clear-cut result had to be expected on the basis of the correlation calculations:

\section{Factor 1: Avoidance}

This avoidance factor summarizes above all the actional and cognitive avoidance actions. Avoidance means that the individuals concerned "avoid dealing

Table 11. Helpful mean values for the behaviour shown.

\begin{tabular}{cccc}
\hline & M & s & n \\
\hline Cognitive engagement & 3.3 & 0.59 & 296 \\
Actional engagement & 3.1 & 0.55 & 290 \\
Cognitive avoidance & 2.1 & 0.9 & 231 \\
Actional avoidance & 2.4 & 0.89 & 287 \\
\hline
\end{tabular}

Legend: $\mathrm{M}=$ Mean; $\mathrm{s}=$ Standard deviation; $\mathrm{n}=$ Number of respondents.

Table 12. Rotated factor matrix.

\begin{tabular}{ccc}
\hline & Factor 1 & Factor 2 \\
\hline Actional engagement & & 0.8633 \\
Cognitive engagement & & 0.8529 \\
Actional avoidance & 0.8945 & \\
Cognitive avoidance & 0.8876 & \\
\hline
\end{tabular}


with" the issue, avoid the issue and/or do everything possible not to actively confront the issue. Since both the cognitive component and the active component load on the same factor, this can be interpreted as an internal validation of those ways of reacting.

Factor 2: Confrontation

Here the actional and cognitive acts of confrontation are bundled together. The term "confrontation" initially only refers to the fact that someone confronts the problem and "addresses" it; the ways of "addressing" are taken either cognitively or actionally. Both forms of confrontation load on the same factor which again has to be seen as an indicator of internal validation, without though failing to recognize that the respective form of action is just one side of the "same coin".

It is apparent from these two factors that the avoidance strategies can neatly be differentiated from the confrontation strategies. These two factors form the basis of the following calculations.

\section{Relationships between Coping Behaviours of Career Counsellors and Framework Conditions in the Employment Agencies, the Counselling Activity, the Personal Situation and Education and Training}

Social, economic and political conditions today demand that career counsellors offer simultaneously support and solutions to problems. High demands are placed on them (Ertelt et al., in press). In addition, there are areas of work that have become important due to social and economic changes and that have a bearing on today's world of work such as the integration of people with disabilities and refugees into the labour market or the further training and qualification of employees in their workplaces e.g. (Ertelt et al., 2021). This work requires career counsellors to be competent in the use of conflict management strategies. As great importance is attached to conflict management strategies, this presupposes that career counsellors are well trained as well as highly motivated and willing to undertake further training (Seifried et al., 2021). In addition they need suitable framework conditions within their institution in order to be able to provide adequate career and further education counselling (NICE, 2016).

In this context, the following areas are examined for relationships with regard to the two factors of engagement and avoidance and corresponding hypotheses are formulated:

- Education and training

On one hand, career counsellors who have followed a "wrong" practice model during training and have not attended any further training will show increased avoidance reactions to stressful situations. On the other hand, it is assumed that career guidance counsellors who regard an academic grounding, personality development and action competence as important training goals, will pursue engagement reactions to resolve a conflict.

- Vocational counselling competence 
Career counsellors who promote the competences and qualifications of their clients, who have a large repertoire of counselling competences and who are aware of the importance of dealing with the needs of their clients, will increasingly pursue engagement strategies.

- Framework conditions

Career counsellors who have more time to search for and to provide information and counselling to clients with more difficult problems, will primarily demonstrate engagement strategies in conflict situations.

- Personal situations

Career counsellors who are dissatisfied with their career counselling and who want to change this, will increasingly pursue engagement strategies.

These differentiated patterns of correlation between education and training, career counselling, framework conditions and personal situations on one hand, and coping behaviour on the other, are presented below as examples based on two regression analyses (Figure 1 and Figure 2).

The first regression calculation includes the factor value "engagement" as a criterion which is derived from the following five remaining predictors ranked according to their importance for the explanation of the criterion:

- Information is comprehensively available to clients.

- Importance of scientific basis for practice.

- Heterogeneous client base.

- Satisfaction with counselling practice.

- Importance of engagement with clients as regards the behaviour exhibited.

Between these five predictors and the criterion there is an attributed variance of $33 \%$ (population estimate of the square of the multiple correlation coefficient).

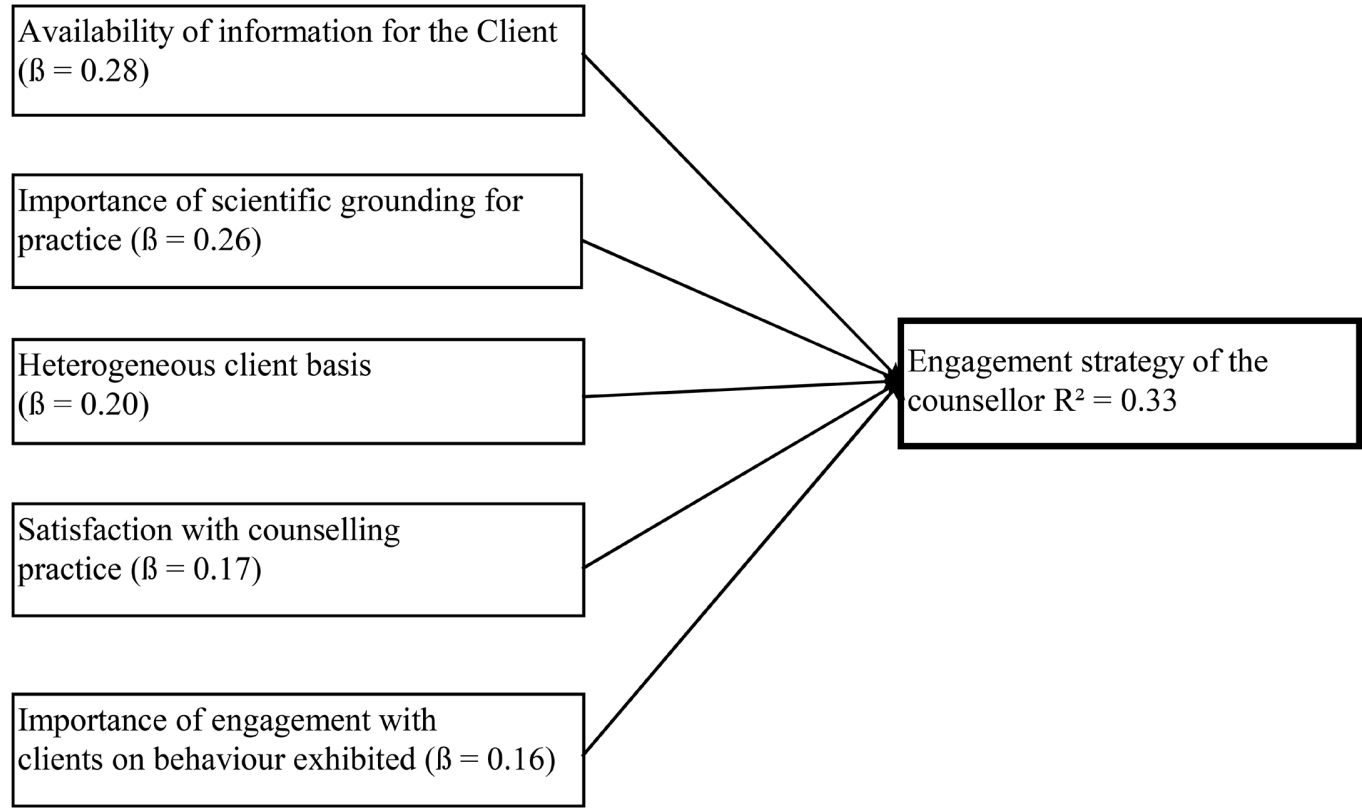

Figure 1. Regression analysis with the criterion engagement. 
Figure 1 confirms the hypotheses that career counsellors who use engagement strategies to manage conflict are more likely to state that they have comprehensive information to give to their clients, that they have a more heterogeneous client base, that they engage with their clients about the behaviour exhibited, that a scientific grounding is important for their practice, and that they are more likely to be dissatisfied with their own counselling.

In the second regression calculation, "avoidance" enters as a dependent factor as a criterion which is derived from the following remaining three predictors ranked according to their importance for the explanation of the criterion:

- Importance of practice in training.

- Further training on counselling competence.

- Satisfaction with counselling practice.

Between these three predictors and the criterion, there is an attributed variance of $22 \%$.

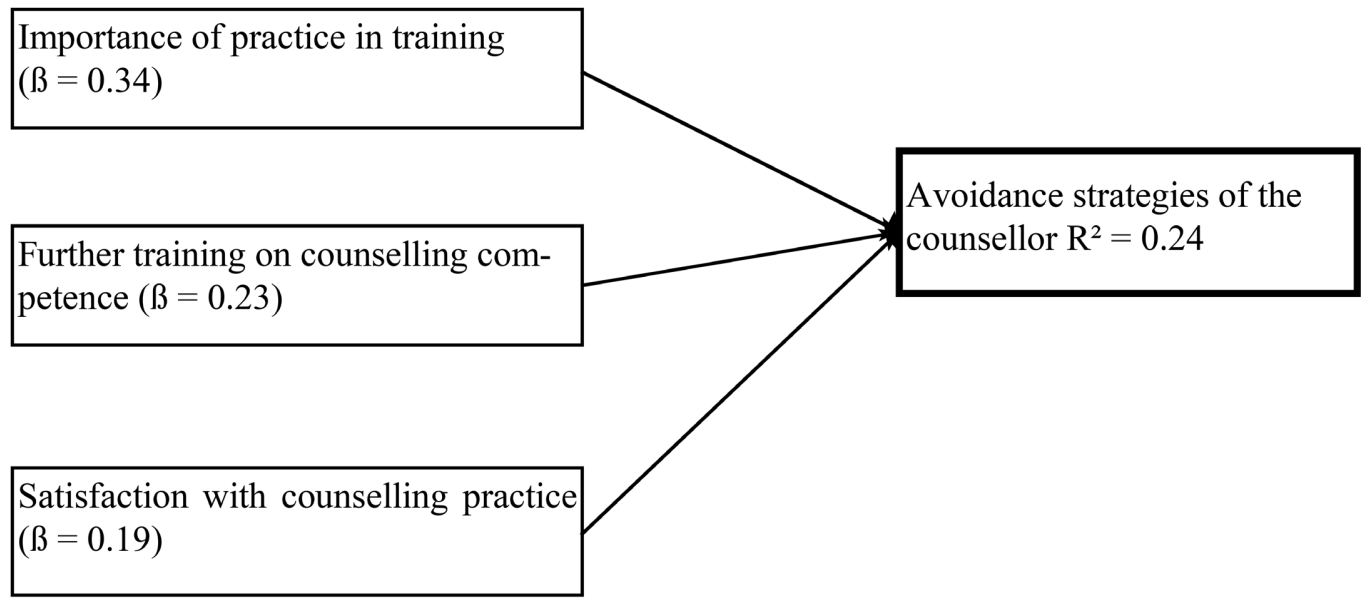

Figure 2. Regression analysis with the criterion avoidance.

Figure 2 shows the following picture: career counsellors who use avoidance strategies to deal with conflict are more likely to say that they consider the practical approach in training to be important, that they have not attended any further training on counselling competence and they are satisfied with their counselling practice.

\section{Summary and Discussion}

According to the heuristic model (Filipp, 1981) and the nine-component model (Jäger, 1989), coping behaviour is a processual event. However, when in action, the individual often does not know why he or she displays a particular behaviour. It is after some time only that the individual becomes aware of the significance of this behaviour. At the beginning of the coping phase, many people react with avoidance behaviour. It is only later on that they deal with the problem. Avoidance and confrontation are not simply two different coping reactions but they fulfil different functions in the coping process (Katz \& Schmidt, 1991). 
However, it seems reasonable to assume that only those individuals who deal with a problem cognitively and also implement this actionally, can actually solve the problem. If a person avoids dealing with an unpleasant situation cognitively, he or she will not show any behaviour that can lead to a solution to the problem.

Coping strategies are in relation to counselling behaviour in conflict situations of great importance. This refers not only to the behaviour of the clients but also to the behaviour of the counsellors who supervise and counsel them.

In everyday professional life, career counsellors are confronted with a variety of conflict situations. These conflicts are not only related to clients but also to problems with colleagues, with a service provider or with the team management.

For the research group "Behaviours of adolescents and young adults in their vocational and study orientation phase and their training and study success", it was important to use the modified coping questionnaire for counsellors to find out which areas of conflict the 346 counsellors were confronted with, which coping strategies they used, how they assessed these strategies and what connections these behaviours had with personal attitudes and positions.

The three most noticeable areas of stress for counsellors are problems with adolescents under 25 years of age and adults over as well as problems with colleagues. Respondents reported that the event was perceived as unpleasant/stressful and was of great significance to them. According to a self-assessment, $72 \%$ of the counsellors were able to cope successfully with the problem. The predictability and duration of the problem had a secondary influence only on successful coping.

301 counsellors (97\%) resorted to actional acts of confrontation, with an average of seven action alternatives. 304 counsellors (99\%) used cognitive strategies of confrontation with an average of 14 alternative actions. 266 counsellors (86\%) reported that they also carried out actional avoidance strategies with an average of three action alternatives. 249 counsellors (81\%) also used cognitive avoidance strategies to solve problems with a mean value of four action alternatives. A correlation calculation showed that all coping actions had a high correlation. Since many counsellors dealt with the problem situation both cognitively and actionally, one can assume in the sense of Katz \& Schmidt (1991) that they were also able to solve the problem and that avoidance and confrontation reactions fulfil different functions in the coping process. According to Jäger (1989) it can also be assumed that the counsellors' behaviour was characterised by a so-called change of action and that they consciously or unconsciously switched between avoidance and confrontation. One reason for these reactions can also be found in their training and further education. When the interviewed counsellors had been trained in counselling skills and conflict resolution strategies during their studies and had attended further training on this topic, they used more actional and cognitive confrontation strategies in a professional counselling situation.

An interesting tendency was found in the answers to the question "How helpful was the behaviour shown?": The cognitive and actional confrontation actions were rated as not being very helpful, the cognitive and actional avoidance actions 
however as quite helpful. Statistical analysis confirmed that counsellors who used avoidance strategies considered this behaviour to be of greater help than the use of confrontation actions. This result corresponded significantly with non-participation in further training on counselling competences and conflict resolution.

Two regression analyses yielded the following results: Career counsellors who used conflict resolution strategies were more likely to say that they had comprehensive information for their clients, that they were dealing with a heterogeneous client base, that it was important for them to discuss the behaviour exhibited by their clients, that they considered a scientific grounding to be important for practice, and that they were more likely to be dissatisfied with their own counselling. However, career counsellors who used avoidance strategies to deal with conflicts were more likely to say that they considered the practical approach in training to be important, that they had not attended any further training on counselling and that they were satisfied with their own counselling.

In summary, the following thesis can be formulated: If the curriculum of the studies and further training places great emphasis on the teaching of counselling competences, which include conflict resolution strategies, the career counsellors concerned were more able and/or more willing to apply conflict resolution actions in conflict situations, especially with clients. Career guidance counsellors who valued practical experience as an important element in their studies showed avoidance behaviour in conflict situations in particular, and especially when dealing with clients and colleagues. It may be that these career counsellors orientated themselves on a wrong practice model and have an incompatible image of dayto-day counselling i.e. they had learned from a model unsuitable to them.

Finally, it can be assumed that career counsellors who want to positively change situations in their counselling work or who are dissatisfied with their current counselling service, prefer to use cognitive and actional conflict solving management.

\section{Conflicts of Interest}

The authors declare no conflicts of interest regarding the publication of this paper.

\section{References}

Behfar, K. J., Mannix, E. A., Peterson, R. S. \& Trochim, W. M. (2011). Conflict in Small Groups: The Meaning and Consequences of Process Conflict. Small Group Research, 42, 127-176. https://doi.org/10.1177/1046496410389194

Dubow, E. F. \& Filipp, M. (2011). Coping. In B. B. Bradfort, \& M. J. Prinstein (Eds.), Encyclopedia of Adolescence (pp. 109-118). Elsevier Academic Press. https://doi.org/10.1016/B978-0-12-373951-3.00107-1

Ertelt, B.-J., Frey, A., Hochmuth, M., Ruppert, J. J., \& Seyffer, S. (2021). Apprenticeships as a Unique Shaping Field for the Development of an Individual Future-Oriented "Vocationality”. Sustainability, 13, Article ID: 2279. https://doi.org/10.3390/su13042279 
Ertelt, B.-J., Schulz, W. E., \& Frey, A. (in press). Handbook of Counselling Competence. An Introduction to Different Counselling Models. Springer.

Filipp, S.-H. (1981). Ein allgemeines Modell für die Analyse kritischer Lebensereignisse. In S.-H. Filipp (Ed.), Kritische Lebensereignisse (pp. 3-47). Urban und Schwarzenberg.

Frey, A., \& Ruppert, J.-J. (2020). Gelingensfaktoren für einen erfolgreichen Start ins Berufsleben (unveröffentlichter Forschungsbericht). University of Applied Labour Studies.

Jäger, R. S. (1989). Diagnostik von Belastung und Bewältigung. In G. Ziegler, R. S. Jäger, \& I. Schüle (Ed.), Krankheitsverarbeitung bei Tumorpatienten (pp. 76-91). Enke.

Katz, P., \& Schmidt, A. R. (1991). Wenn der Alltag zum Problem wird. Verlag für angewandte Psychologie.

Labrague, L. J., McEnroe-Petitte, D. M., Papathanasiou, I. V., Edet, O. B., Tsaras, K., Leocadio, M. C., Colet, P., Kleisiaris, C. F., Fradelos, E. C., Rosales, R. A., Santos-Lucas, K. V., \& Velacaria, P. I. (2018). Stress and Coping Strategies among Nursing Students: An International Study. Journal of Mental Health, 27, 402-408.

https://doi.org/10.1080/09638237.2017.1417552

Lumsden, D. P. (1975). Towards a Systems Model of Stress: Feedback from an Anthropological Study of the Impact of Ghana's Volta River Project. In I. G. Sarason, \& C. D. Spielberger (Eds.), Stress and Anxiety (Band 2) (pp. 191-222). Wiley.

Neubauer, G., \& Winter, R. (2007). Geschlechter differenzierende Aspekte in Angeboten der Gewaltprävention in der außerschulischen Jugendarbeit. Deutsches Jugendinstitut.

NICE (2016). European Competence Standards for the Academic Training of Career Practitioners. NICE Handbook Volume 2. Barbara Budrich.

Obi, J. S., \& Obineli, A. S. (2015). Psychological Strategies for Resolving Interpersonal Conflicts among Administrators in Tertiary Institutions. Journal of Education amd Practice, 6, 46-51.

Seifried, J., Brodsky, A., \& Sailmann, G. (2021). Learning through Workplace Experiences in Dual Higher Education. In A. Frey \& M. Scharpf (Eds.), Vocational Guidance in International Comparison. In Honour of the 80th Birthday of Prof. Dr. Bernd-Joachim Ertelt (pp. 435-449). W. Bertelsmann Verlag.

Stephenson, E., King, D. B., \& DeLongis, A. (2016). Coping Process. In G. Fink (Ed.), Stress: Concepts, Cognition, Emotion, and Behavior (pp. 359-364). Academic Press. https://doi.org/10.1016/B978-0-12-800951-2.00045-5

Ulrich, A. (2020). Personal and Life-World Resources of Young People in the Career-Choice Phase and Their Effects on the Perception of Stress. Berufs-und Wirtschaftspädagogik online, 38, 1-19.

Ulrich, A. (2021). Stress und Coping in der Berufswahlphase. Dissertation an der Technischen Universität in Kaiserslautern. Kaiserslautern: Universität.

Wang, N., \& Wu, G. (2020). A Systematic Approach to Effective Conflict Management for Program. Sage Open, 1, 1-15. https://doi.org/10.1177/2158244019899055 